\title{
(2) OPEN ACCESS \\ Patient outcomes after hospitalisation with COVID-19 and implications for follow-up: results from a prospective UK cohort
}

\author{
David T Arnold ำ , ${ }^{1}$ Fergus W Hamilton, ${ }^{1}$ Alice Milne, ${ }^{1}$ Anna J Morley, ${ }^{1}$ Jason Viner, ${ }^{1}$ \\ Marie Attwood ${ }^{2}$ Alan Noel, ${ }^{2}$ Samuel Gunning, ${ }^{1}$ Jessica Hatrick, ${ }^{1}$ Sassa Hamilton, ${ }^{1}$ \\ Karen T Elvers, ${ }^{3}$ Catherine Hyams 이, ${ }^{1}$ Anna Bibby, ${ }^{1}$ Ed Moran, ${ }^{1}$ Huzaifa I Adamali, ${ }^{1}$ \\ James William Dodd, ${ }^{1}$ Nicholas A Maskell, ${ }^{1}$ Shaney L Barratt ${ }^{1}$
}

${ }^{1}$ Academic Respiratory Unit, North Bristol NHS Trust, Bristol, UK

${ }^{2}$ Bristol Centre for Antimicrobial Research (BCARE), North Bristol NHS Trust, Bristol, UK

${ }^{3}$ Medicines Discovery Institute Cardiff, Cardiff University, Cardiff, UK

\section{Correspondence to}

Dr Nicholas A Maskell, Academic Respiratory Unit, North Bristol NHS Trust, Bristol BS10 5NB, UK; Nick.Maskell@bristol.ac.uk

DTA and FWH are joint first authors.

Received 26 August 2020 Revised 29 September 2020 Accepted 5 October 2020 Published Online First 3 December 2020

\section{SLinked}

- http://dx.doi.org/10.1136/ thoraxjnl-2020-215818 - http://dx.doi.org/10.1136/ thoraxjnl-2020-216226

Check for updates

(C) Author(s) (or their employer(s)) 2021. Re-use permitted under CC BY-NC. No commercial re-use. See rights and permissions. Published by BMJ.

To cite: Arnold DT Hamilton FW, Milne A, et al. Thorax 2021;76:399-401.

\section{ABSTRACT}

The longer-term consequences of SARS-CoV-2 infection are uncertain. Consecutive patients hospitalised with COVID-19 were prospectively recruited to this observational study ( $n=163)$. At 8-12 weeks postadmission, survivors were invited to a systematic clinical follow-up. Of 131 participants, 110 attended the follow-up clinic. Most (74\%) had persistent symptoms (notably breathlessness and excessive fatigue) and limitations in reported physical ability. However, clinically significant abnormalities in chest radiograph, exercise tests, blood tests and spirometry were less frequent (35\%), especially in patients not requiring supplementary oxygen during their acute infection (7\%). Results suggest that a holistic approach focusing on rehabilitation and general well-being is paramount.

\section{INTRODUCTION}

Limited studies exist on the longer-term outcomes of patients admitted to the hospital due to COVID-19. Although several guidelines have been published, ${ }^{12}$ these are based on extrapolation of complications from other coronavirus infections. ${ }^{34}$ Disease-specific data on the outcomes for survivors of COVID-19 are essential to properly inform guidelines.

We report a prospectively recruited UK cohort of hospitalised patients with COVID-19. Consecutively hospitalised patients were recruited at diagnosis and followed-up at 8-12 weeks with a face-to-face medical review, spirometry, exercise test, blood tests, chest radiograph and assessment of the health-related quality of life (HRQoL).

\section{METHODS}

\section{Subjects}

Patients were recruited from the Diagnostic and Severity markers of COVID-19 to Enable Rapid triage (DISCOVER) study, a single-centre prospective study (Bristol, UK) recruiting consecutive patients ( $\geq 18$ years of age) admitted with COVID-19. Ethics approval was via South Yorkshire (REC: 20/YH/0121). The inclusion criteria were a positive PCR result for SARS-CoV-2 or a clinico-radiological diagnosis of COVID-19 disease (see online supplementary material).

\section{Baseline assessment and 28-day follow-up}

Baseline demographics, comorbidities and blood test results were extracted from the medical record. At 28 days, survivors were defined as having had severe disease (invasive mechanical ventilation, non-invasive ventilation and/or intensive care admission), moderate disease (supplementary oxygen during admission) or mild disease (no supplementary oxygen or intensive care).

\section{Face-to-face outpatient follow-up}

All patients who survived were offered follow-up at a respiratory outpatient clinic (except for nursing home residents or current hospital inpatients) 8-12 weeks after their hospital admission. Those attending had a face-to-face review with a respiratory clinician, chest radiograph (CXR), spirometry, exercise testing (using $1 \mathrm{~min}$ sit to stand test (STS)), ${ }^{5}$ routine blood tests, and SF-36 quality-of-life and Warwick-Edinburgh Mental Wellbeing Scales (WEMWBS) questionnaires. The severity and nature of abnormalities detected on CXR were scored and described (online supplementary material for full details). ${ }^{6}$

\section{RESULTS}

Between 30 March and 3 June 2020, 163 participants with COVID-19 were recruited. Of these, 19 patients died and 13 were inpatients from hospital/nursing home. The remaining 131 were invited for follow-up and 110 attended. Eighteen declined: ongoing shielding $(n=10)$, being care providers $(n=3)$ and felt unnecessary $(n=5)$. Three were uncontactable (see supplementary material: Consolidated Standards of Reporting Trials). Table 1 shows the baseline demographics and clinical outcomes of those who attended follow-up divided by severity of COVID-19 illness (median age 60 years (IQR 46-73); 56\% ( $\mathrm{n}=91)$ male individuals). Patients were followed-up with a median of 83 days (IQR 74-88 days) after hospital admission and 90 days (IQR 80-97 days) after COVID-19 symptom onset.

\section{Symptoms}

Although most symptoms were improving, 81 (74\%) patients reported at least one ongoing symptom: 39\% breathlessness, 39\% fatigue and $24 \%$ insomnia (see figure 1). Sixteen (59\%) patients in the mild COVID-19 group reported ongoing symptoms compared with 49 (75\%) and 16 (89\%) in the moderate and severe group, respectively (figure 2). 


\begin{tabular}{|c|c|c|c|}
\hline Characteristic & $\begin{array}{l}\text { Mild } \\
(\mathrm{n}=27)\end{array}$ & $\begin{array}{l}\text { Moderate } \\
(\mathrm{n}=65)\end{array}$ & $\begin{array}{l}\text { Severe } \\
(\mathrm{n}=18)\end{array}$ \\
\hline \multicolumn{4}{|l|}{ Demographics } \\
\hline Age $(18+)$, years & $47(32-61)$ & $57(48-67)$ & $62(54-71)$ \\
\hline BAME & $5(19 \%)$ & $15(23 \%)$ & $3(19 \%)$ \\
\hline Male & $13(48 \%)$ & $44(68 \%)$ & $11(61 \%)$ \\
\hline BMI (mean) & 31.2 & 32.5 & 32.5 \\
\hline \multicolumn{4}{|l|}{ Comorbidities } \\
\hline T1DM & $1(3.7 \%)$ & $1(1.5 \%)$ & $1(5.6 \%)$ \\
\hline T2DM & $2(7.4 \%)$ & $12(18 \%)$ & $2(11 \%)$ \\
\hline Heart disease & $6(22 \%)$ & $11(17 \%)$ & $3(17 \%)$ \\
\hline Chronic lung disease & $4(15 \%)$ & $16(25 \%)$ & $8(44 \%)$ \\
\hline Severe liver disease & $0(0 \%)$ & $1(1.5 \%)$ & $0(0 \%)$ \\
\hline Severe kidney disease & $1(3.7 \%)$ & $4(6.2 \%)$ & $2(11 \%)$ \\
\hline Hypertension & $4(15 \%)$ & $16(25 \%)$ & $7(39 \%)$ \\
\hline HIV & $0(0 \%)$ & $0(0 \%)$ & $1(5.6 \%)$ \\
\hline \multicolumn{4}{|l|}{ Laboratory testing } \\
\hline $\begin{array}{l}\text { SARS-CoV-2 PCR+ve } \\
\text { (as inpatient) }\end{array}$ & $21(78 \%)$ & $50(77 \%)$ & $10(56 \%)$ \\
\hline $\begin{array}{l}\text { SARS-CoV-2 lgG+ve (Abbott/Roche) } \\
\text { (at follow-up) }\end{array}$ & $18(67 \%)$ & $56(86 \%)$ & $15(83 \%)$ \\
\hline $\begin{array}{l}\text { SARS-CoV-2 PCR-ve } \\
\text { (as inpatient) and SARS-CoV-2 } \\
\text { lgG-ve (at follow-up) }\end{array}$ & $3(11 \%)$ & $6(9 \%)$ & $2(11 \%)$ \\
\hline \multicolumn{4}{|l|}{ Outcomes } \\
\hline Admission NEWS score (IQR) & $2(1-3)$ & $4(2-6)$ & $5(4-8)$ \\
\hline $\begin{array}{l}\text { Radiographic severity score on } \\
\text { admission chest radiograph }\end{array}$ & $0(0-2)$ & $3(1.75-4)$ & $3(1.25-6)$ \\
\hline $\begin{array}{l}\text { Invasive or non-invasive ventilation } \\
\text { required }\end{array}$ & $0(0 \%)$ & $0(0 \%)$ & $16(89 \%)$ \\
\hline Supplementary oxygen required & $0(0 \%)$ & $65(100 \%)$ & $18(100 \%)$ \\
\hline Hospital length of stay, days & $2(1-4)$ & $5(2-8)$ & $10(7-17)$ \\
\hline
\end{tabular}

\section{Radiology}

Of the $15 / 110(14 \%)$ patients with abnormal follow-up radiographs ( $\mathrm{n}=10$ moderate group, $\mathrm{n}=5$ severe group), 2 had worsened from hospital admission with higher radiographic severity scores (both had known previous interstitial lung disease). Findings seen included consolidation (one patient), reticulation (eight patients), atelectasis (five patients) and pleural effusion (one patient). Highresolution CT (HRCT) scans performed on the basis of the clinical, spirometric or radiological findings (nine patients) showed fibrotic changes in two patients with moderate disease at baseline (other HRCT results: normal (four), minor persistent ground glass changes (two), pleural effusion(one)).

\section{Pulmonary function testing}

Eleven patients had restrictive spirometry and 15 had a significant desaturation on the STS test, all within the severe or moderate group (see the online supplementary material).

\section{Health-related quality of life}

SF-36 scores demonstrated a reduction in reported health status across all domains compared with age-matched population norms. ${ }^{7}$ In particular, physical scores were significantly lower in the severe cohort compared with mild/moderate (see the online supplementary material). In contrast, WEMWBS scores were comparable with published population norms, ${ }^{8}$ with no significant difference between groups.

\section{Blood results}

Thirty-five (32\%) patients had significantly deranged liver $(\mathrm{n}=12)$ or renal $(n=9)$ function recorded during admission. All improved and 32 of 35 results had returned to baseline. Two additional patients had an ongoing lymphopenia and two were with a C-reactive protein level greater than $10 \mathrm{mg} / \mathrm{L}$.

\section{DISCUSSION}

Over 130000 people have been admitted to hospital with COVID-19 in the UK alone. As admission rates begin to fall, the potential impact of 'post-COVID' syndromes on patients and the health services is becoming apparent. We present a UK cohort study of consecutively recruited patients hospitalised with COVID-19

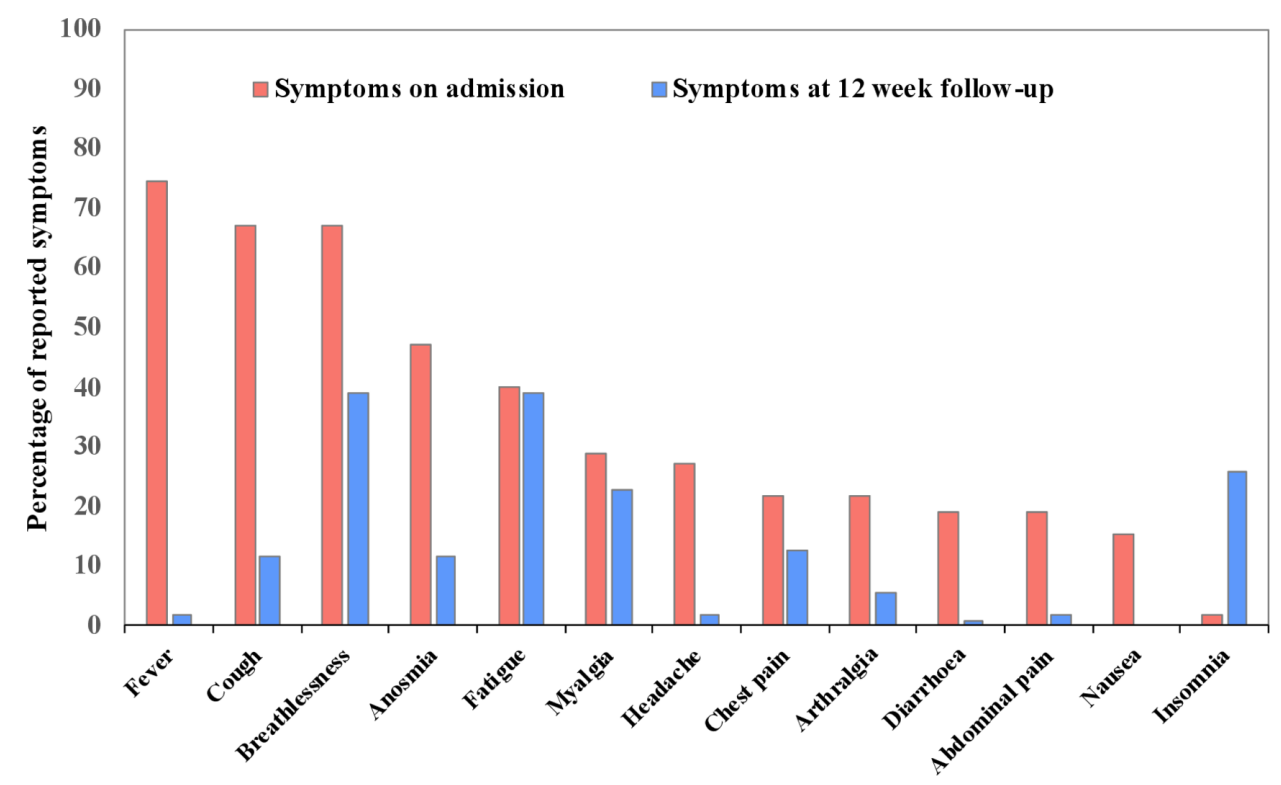

Figure 1 Frequency of symptoms reported at a 12-week follow-up compared with hospital admission. 


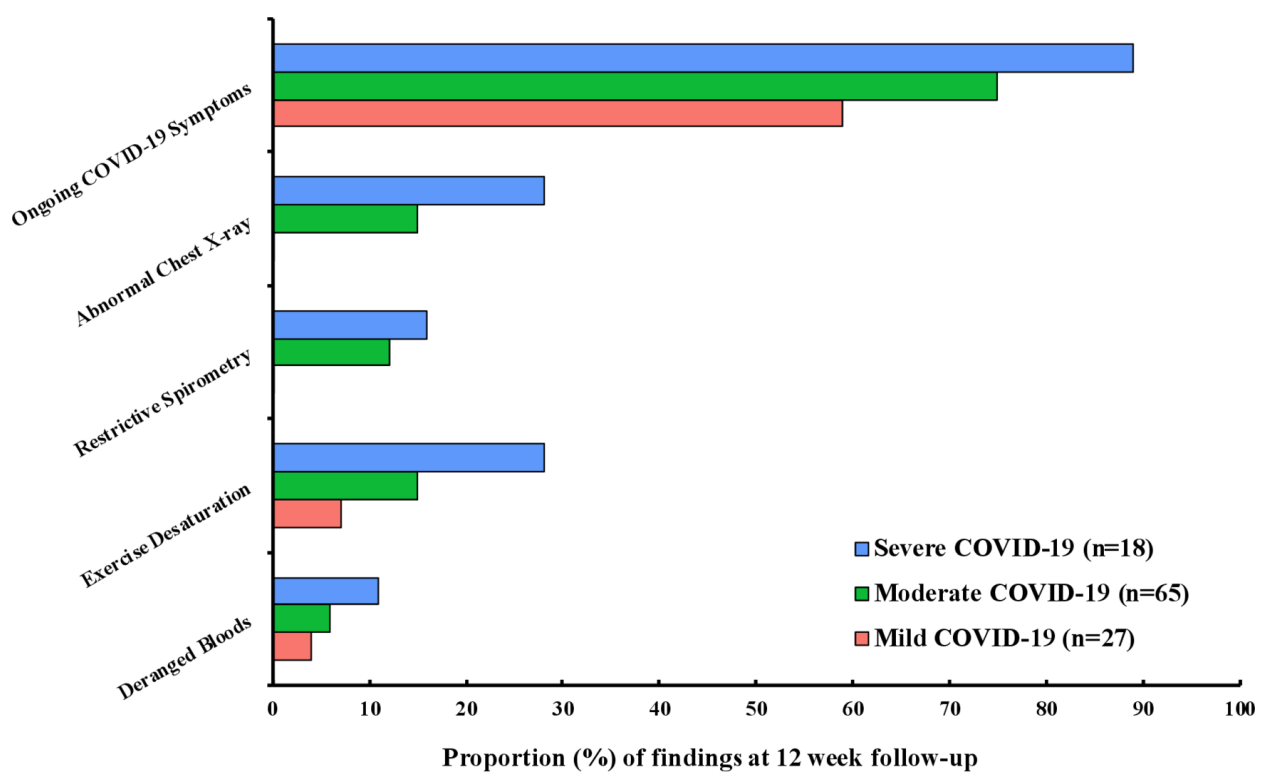

Figure 2 Summary of symptomatology and clinical results by disease severity.

and systematically assessed after discharge. Our key finding is that nearly three-quarters of patients remain symptomatic at 3 months, while clinical abnormalities were rare in mild disease.

Few studies have reported results from systematic prospective follow-up after hospitalisation. Our findings are in keeping with an Italian cohort of patients asked to recall their admission symptoms and HRQoL at a median of 60 days postdischarge, finding that $87 \%$ had at least one ongoing symptom with fatigue $(53 \%)$ and shortness of breath $(43 \%)$ predominating. ${ }^{9}$ Similar findings have been demonstrated in other follow-up studies. ${ }^{10}$

The British Thoracic Society (BTS) COVID-19 Guidance advises follow-up guidance depending on whether the patient required intensive/higher care versus ward/community care (equivalent to severe vs mild/moderate in this cohort). ${ }^{1}$ For mild/moderate disease, BTS recommends virtual follow-up with a CXR. This study demonstrated a low likelihood of follow-up CXR abnormalities in patients not requiring oxygen for their acute infection, suggesting that this approach may not be necessary.

The wide range of symptoms and reduced HRQoL seen in this study re-enforces the importance of a holistic approach advocated by the BTS and other guidelines. ${ }^{1}{ }^{2}$ All patients in our follow-up clinics were offered a referral to specialist psychological support services.

We recognise potential limitations of this study including the single-centre design and relatively small patient numbers that may limit the generalisability of results. Second, patients residing in a nursing home or hospital inpatients were not followed-up in line with local infection control protocols.

The study demonstrates the persistence of symptoms at 8-12 weeks in the majority of patients, even those admitted with mild disease. There was a reassuring improvement in clinical measures with only a minority having abnormal biochemical, radiological or spirometric tests. These results provide information useful to clinicians caring for survivors of COVID-19 disease. The role(s) of rehabilitation and/or psychological services in the management of such patients warrant research.

Twitter Fergus W Hamilton @gushamilton, Catherine Hyams @cathyams and James William Dodd @theotherdodd

Acknowledgements The authors would like to thank the North Bristol NHS Trust COVID-19 research team as well as the University of Bristol UNCOVER group for guidance in data analysis and study design. They would also like to thank all the patients who took part in the DISCOVER study.

Contributors DTA, SLB, NAM, JWD and FWH generated the research question and analysis plan. AM, AJM, MA, AN, CH, AB, EM, HA, JWD, NAM, DTA, FWH were involved in data collection and clinical appointments. SG, JH, SH and KTE were involved in data analysis. All authors were involved in the final manuscript preparation.

Funding The DISCOVER study was supported by donations to Southmead Hospital Charity (Registered Charity Number: 1055900).

Competing interests None declared.

Patient consent for publication Not required.

Provenance and peer review Not commissioned; externally peer reviewed.

Open access This is an open access article distributed in accordance with the Creative Commons Attribution Non Commercial (CC BY-NC 4.0) license, which permits others to distribute, remix, adapt, build upon this work non-commercially, and license their derivative works on different terms, provided the original work is properly cited, appropriate credit is given, any changes made indicated, and the use is non-commercial. See: http://creativecommons.org/licenses/by-nc/4.0/.

\section{ORCID iDs}

David T Arnold http://orcid.org/0000-0003-3158-7740

Catherine Hyams http://orcid.org/0000-0003-3923-1773

\section{REFERENCES}

1 George PM, Barratt SL, Condliffe R, et al. Respiratory follow-up of patients with COVID-19 pneumonia. Thorax 2020;75:1009-16.

2 Greenhalgh T, Knight M, A'Court C, et al. Management of post-acute covid-19 in primary care. BMJ 2020;370:m3026.

3 Das KM, Lee EY, Singh R, et al. Follow-Up chest radiographic findings in patients with MERS-CoV after recovery. Indian J Radiol Imaging 2017;27:342-9.

4 Hui DS, Wong KT, Ko FW, et al. The 1-year impact of severe acute respiratory syndrome on pulmonary function, exercise capacity, and quality of life in a cohort of survivors. Chest 2005;128:2247-61.

5 Briand J, Behal H, Chenivesse C, et al. The 1-minute sit-to-stand test to detect exercise-induced oxygen desaturation in patients with interstitial lung disease. Ther Adv Respir Dis 2018;12:1753466618793028.

6 Wong HYF, Lam HYS, Fong AH-T, et al. Frequency and distribution of chest radiographic findings in patients positive for COVID-19. Radiology 2020;296:E72-8.

7 Burholt V, Nash P. Short form 36 (SF-36) health survey questionnaire: normative data for Wales. J Public Health 2011;33:587-603.

8 WEMWBS population norms in health survey for England data 2011, 2011. Available: https://www.corc.uk.net/media/1243/wemwbs_populationnorms2011.pdf

9 Carfi A, Bernabei R, Landi F, et al. Persistent symptoms in patients after acute COVID-19. JAMA 2020;324:603

10 Halpin SJ, Mclvor C, Whyatt G, et al. Postdischarge symptoms and rehabilitation needs in survivors of COVID-19 infection: a cross-sectional evaluation. J Med Virol 2020. doi:10.1002/ jmv. 26368 